\title{
RENDERING VIDEO ADVERTISING DENGAN ADOBE AFTER EFFECTS DAN PHOTOSHOP
}

\author{
Dewi Maharani ${ }^{1}$, Muhammad Hotami ${ }^{2}$ \\ ${ }^{I}$ Manajemen Informatika, AMIK Royal Kisaran \\ ${ }^{2}$ Teknik Komputer, STMIK Logika Medan \\ Jl. Imam Bonjol No.179 Kisaran, Telp: 0623-42451, Faksimili: 0623-42366 \\ e-mail :dewimaharani15@gmail.com
}

\begin{abstract}
Abstrak
Dunia multimedia khususnya Advertising saat ini semakin ramai, terbukti dengan hadirnya video atau film-film animasi. Film atau video animasi yang ramai sekarang tentu sebuah video animasi dengan kualitas yang sangat baik, mulai dari penggambaran tokoh, special efek, penataan suara dan lain sebagainya. Kualitas video yang baik juga tentu tidak terlepas dari ribuan frame yang dibuat dengan detail sangat tinggi oleh para desainer. Adanya Advertising pada sebuah Lembaga Pendidikan dapat lebih memperkenalkan serta menarik hati banyak orang hingga target pendidikan dalam penyebaran ilmu pengetahuan serta banyaknya orang yang masuk kedalam untuk mendaftar dan belajar di kampus STMIK Logika Medan semakin meningkat pesat. Dengan penggunaan software adobe After Effects dan Photoshop, maka proses rendering video advertising akan menjadi sesuai dengan keinginan.
\end{abstract}

Kata Kunci: Rendering, Video, Advertising, After Effects, Photoshop.

\section{PENDAHULUAN}

Dunia Advertising saat ini semakin ramai, terbukti dengan hadirnya video atau film-film animasi. Film atau video animasi yang ramai sekarang tentu sebuah video animasi dengan kualitas yang sangat baik, mulai dari penggambaran tokoh, special efek, penataan suara dan lain sebagainya. Kualitas video yang baik juga tentu tidak terlepas dari ribuan frame yang dibuat dengan detail sangat tinggi oleh para desainer. Beberapa tahapan pokok dalam pembuatan film animasi ada tiga tahapan. Yaitu Pra-produksi, produksi dan pasca produksi. Proses Rendering merupakan proses untuk mengubah file project Adobe After Effect menjadi video. Dalam sebuah animasi, proses rendering dilakukan Frame-by-frame. Setelah sebuah composition di-render, maka program akan mengubah frame-frame yang telah di render tersebut menjadi sebuah file

Perusahaan, Akademik maupun organisasi sangat membutuhkan suatu media periklanan (Advertising) yang digunakannya untuk kepentingan tertentu. Advertising yang baik adalah Advertising yang bisa mempengaruhi sasaran tertentu sehingga memberikan dampak positif untuk perusahaan atau organisasi tersebut. Advertising juga bisa menggunakan berbagai cara, mulai dari media cetak sampai media elektronik. Bisa berupa katalog, poster, website, video, dan lain sebagainya.

Untuk itu Peneliti mengembangkan dan meningkatkan ilmu yang berhubungan dengan informasi kampus, desain grafis, Advertising dan video agar mampu membuat Video yang bagus dengan memanfaatkan bantuan software - software gratis khususnya dalam pembuatan Advertising Kampus STMIK Logika. Seperti merancang dan membuat advertising dengan merendering video. Membangun sebuah Video Advertising yang menarik, informatif dan interactive dengan menggabungkan Desain Grafis Adobe Photoshop dengan Adobe Effects.

Penelitian ini menggunakan deskriftif kualitatif, yang bertujuan mengungkap fakta, keadaan, fenomena, variabel dan keadaan yang terjadi saat penelitian berjalan dan menyuguhkan apa adanya.

\section{STUDI PUSTAKA}

\subsection{Rendering}

Rendering merupakan sebuah proses untuk menghasilkan sebuah citra 2D dari data 3D. Prose ini bertujuan untuk untuk memberikan visualisasi pada user mengenai data 3D tersebut melalui monitor atau pencetak yang hanya dapat menampilkan data 2D. Penyaji video software yang memproses file video dan mengirimkannya secara berurutan untuk tampilan video controller card untuk ditampilkan pada layar komputer. Sebuah contoh dari penyaji video, adalah KMV - 7 yang digunakan oleh DirectShow Microsoft . Contoh dari video penyaji UNIX adalah salah satu wadah dalam Gstreamer. [1]

Rendering merupakan proses yang paling menyita waktu dikarenakan membutuhkan dukungan perangkat keras dan perangkat lunak dengan spesifikasi yang tinggi. Tetapi, hal ini akan dapat menimbulkan masalah dalam keuangan dikarenakan pembelian perangkat dengan spesifikasi tinggi atau pun hanya untuk melakukan upgrade komputer yang digunakan untuk proses rendering. 


\subsection{Photoshop}

Adobe Photoshop, atau biasa disebut Photoshop, adalah perangkat lunak editor citra buatan Adobe Systems yang dikhususkan untuk pengeditan foto/gambar dan pembuatan efek. Perangkat lunak ini banyak digunakan oleh fotografer digital dan perusahaan iklan sehingga dianggap sebagai pemimpin pasar (market leader) untuk perangkat lunak pengolah gambar/foto, dan, bersama Adobe Acrobat, dianggap sebagai produk terbaik yang pernah diproduksi oleh Adobe Systems. [2]

Photoshop tersedia untuk Microsoft Windows, Mac OS X, dan Mac OS; versi 9 ke atas juga dapat digunakan oleh sistem operasi lain seperti Linux dengan bantuan perangkat lunak tertentu seperti CrossOver. Meskipun pada awalnya Photoshop dirancang untuk menyunting gambar untuk cetakan berbasis-kertas, Photoshop yang ada saat ini juga dapat digunakan untuk memproduksi gambar untuk World Wide Web. Beberapa versi terakhir juga menyertakan aplikasi tambahan, $\underline{\text { Adobe }}$ ImageReady, untuk keperluan tersebut. Photoshop juga memiliki hubungan erat dengan beberapa perangkat lunak penyunting media, animasi, dan authoring buatan-Adobe lainnya. File format asli Photoshop, .PSD, dapat diekspor ke dan dari Adobe ImageReady. Adobe Illustrator, Adobe Premiere Pro, After Effects dan Adobe Encore DVD untuk membuat DVD profesional, menyediakan penyuntingan gambar non-linear dan layanan special effects seperti background, tekstur, dan lainlain untuk keperluan televisi, film, dan situs web. Sebagai contoh, Photoshop CS dapat digunakan untuk membuat menu dan tombol (button) DVD.

\subsubsection{Preferensi untuk Seleksi Foto}

Seleksi merupakan salah satu tugas yang cukup berat, baik jika dilihat dari sisi pengguna maupun perangkat. Sebagai contoh, "beban" kerja komputer ketika anda membuat seleksi didalam kanvas akan bertambah berat seiring dengan tingkat kerumitan seleksi itu sendiri dan ukuran foto yang saat itu sedang diseleksi. Oleh karena itu, tugas yang utama adalah memastikan sebaik mungkin agar setiap preferensi yang ada di dalam Photoshop terarah dengan baik. Tujuannya hanya satu, agar Photoshop dapat bekerja secara maksimal.

Panel berfungsi untuk membantu proses editing dan pembuatan sebuah desain. Dalam proses seleksi, tidak semua panel yang telah disediakan oleh Photoshop akan anda gunakan. Supaya proses seleksi menjadi lebih efisien, anda perlu mengenali panel-panel yang berkaitan erat dengan proses seleksi, seperti Layers, Channel, Path dan lain sebagainya.

\subsubsection{Metode-Metode Seleksi di Dunia Photoshop}

Urusan seleksi memang merupakan salah satu urusan paling krusial dan penting dalam dunia digital imaging yang meliputin fotografi digital, desain grafis, manipulasi foto, hingga pembuatan ilustrasi. Oleh karena itu, tidak heran jika pepatah kuno, "ada seribu jalan menuju Roma" cocok jika diterapkan dalam dunia Photoshop.

\subsubsection{Seleksi Menggunakan Tool Standar}

Tool dalam Adobe Photoshop adalah alat yang dapat membantu pengguna dalam mengedit. Adobe Photoshop CS3 memilikit 59 tool yang dapat dipakai oleh pengguna. Tool - tool tersebut terdiri dari berbagai macam tool dengan kegunaan yang spesifik. Beberapa tool - tool yang ada di Photoshop antara lain :

1. Menyeleksi Menggunakan Polygonal Tool

2. Menyeleksi Menggunakan Rectangular Marquee Tool

3. Menyeleksi Menggunakan Elliptical Marquee Tool

4. Menyeleksi Menggunakan Magnetic Lasso Tool

5. Menyeleksi Menggunakan Channel

6. Menyeleksi Menggunakan Pen Tool

7. Menyeleksi Menggunakan Panel Path

\subsubsection{Layer Mask}

Layer Mask adalah layer yang diberi mask. Anda bisa menyebut mask dengan sebutan seharihari seperti: topeng, penutup, masker, kostrum ninja dll. Pada intinya, bagian yang tertutup oleh mask atau topeng itu, tidak akan terlihat didalam kanvas.

Cara paling cepat untuk membuat seleksi menggunakan prinsip mask adalah dengan menggunakan layer mask.

\subsubsection{Adobe After Effect}

Adobe After Effect merupakan software pembuat animasi dan special effect yang sangat populer dan sudah diakui kecanggihannya. Kelengkapan fasilitas dan kemampuannya yang luar biasa menjadikan software ini banyak dipakai oleh para animator dan desain grafis karena keberadaannya benar-benar mampu membantu dan memudahkan pemakai dalam menyelesaikan berbagai jenis pekerjaan visual. Adobe After Effects adalah produk piranti lunak yang dikembangkan oleh Adobe, digunakan untuk film dan pos produksi pada video. pada awalnya merupakan sebuah software produk dari Macromedia yang sekarang sudah menjadi salah satu produk Adobe.

Adobe After Effects adalah sebuah software yang sangat profesional untuk kebutuhan Motion Graphic Design. Dengan perpaduan dari bermacam - macam software Design yang telah ada, Adobe After Effects menjadi salah satu software Design yang handal. Standart Effects yang mencapai sekitar 50 macam lebih, yang sangat bisa untuk mengubah dan menganimasikan obyek. Disamping itu, membuat animasi dengan Adobe After Effects, juga bisa dilakukan dengan hanya mengetikkan 
beberapa kode script yang biasa disebut Expression untuk menghasil pergerakan yang lebih dinamis.

\subsection{Animasi}

Animasi adalah pergerakan dinamis suatu komponen ilustrasi yang dibuat menggunakan Adobe After Effects. Dalam membuat animasi nantinya akan berinteraksi dengan keyframe, expressions, graph editor, script. Dengan adobe after effects kita dapat membuat animasi yang digunakan untuk melengkapi efek-efek pada sebuah film.

Penerapan animasi ini nantinya dapat langsung diterapkan pada sebuah klip movie atau digunakan untuk membuat sebuah materi animasi. Sehingga perlu mengetahui tentang format standart television di indonesia dan dinegara-negara lain di Asia, yaitu PAL dan NTSC. Yang dimaksud format disini adalah time frame dan aspect ratio yang digunakan oleh masing-masing standart televisi sebuah negara. Penjelasannya adalah PAL menggunakan frame rate: 25 fps (frame per second) dengan aspect ratio: 3:4. Sedangkan NTSC menggunakan frame rate: $29.7 \mathrm{fps}$ atau dibulatkan menjadi 30 fps dengan Aspect ratio: 16:9.

Biasanya untuk Indonesia menggunakan format standart PAL.

\subsection{Video Advertising}

Video advertising merupakan bentuk iklan yang ditargetkan pada content video. Berbagai format tersedia, termasuk iklan dinamis yang bisa tampil sebelum, setelah, ataupun selama tayangnya content video tertentu. Kelebihan iklannya mudah di ingat karena sama seperti apa yang dipasarkan.

\section{METODE}

\subsection{Analisis Kebutuhan}

\subsubsection{Analisis Perangkat Keras (Hardware)}

Analisis terhadap perangkat keras dilakukan untuk mengetahui perangkat keras yang mendukung untuk merendering suatu video. Beberapa hal penting dari hardware yang diperlukan guna melakukan rendering video, yaitu:

1. Prosesorlah yang menentukan kecepatan render, karena pada saat prosesor render dimulai maka kerja akan diambil alih sepenuhnya oleh processor dengan dibantu RAM, semakin banyak core maka akan semakin cepat render-nya.

2. Memori yang digunakan sebaiknya berkapasitas besar karena semua program grafis, baik 3D maupun 2D terkenal rakus akan memori.

3. Motherboad yang digunakan sebaiknya menggunakan performa dan kapasitas yang massive.

\subsubsection{Analisis Perangkat Lunak (Software)}

Sebagai pertimbangan untuk merendering

video digunakanlah perangkat lunak yang disesuaikan juga dengan perangkat kerasnya. Software yang digunakan yaitu Photoshop, Photodex Proshow Producer dan Adobe After Effect. After Effect digunakan untuk merubah dan menganimasikan objek. Pada After Effect, terdapat beberapa fasilitas yang dimiliki oleh beberapa software lainya. Salah satunya adalah After Effects terdapat tool untuk membuat shape (seperti yang terdapat pada photoshop). Pada After Effects terdapat keyframe seperti yang terdapat pada flash (cara menganimasikannya juga hampir sama).

\subsection{Analisis Sumber Daya Manusia (Brainware)}

Analisis ini meliputin individu yang terlibat langsung dalam pembuatan rendering video. Manusia yang sebagai pembuat, diharapkan dapat menyampaikan maksud tujuan atau isi dalam bentuk video. Hal ini penting dilakukan dikarenakan memiliki peranan penting serta menjadi salah satu hal pokok dalam kegiatan perancangan video advertising. Tanpa adanya sumber daya manusia yang mampu juga berkualitas maka ketersediaan software dan hardware diatas tidak akan berarti.

\subsection{Desain Secara Umum \\ 3.6.1 Diagram Konteks}

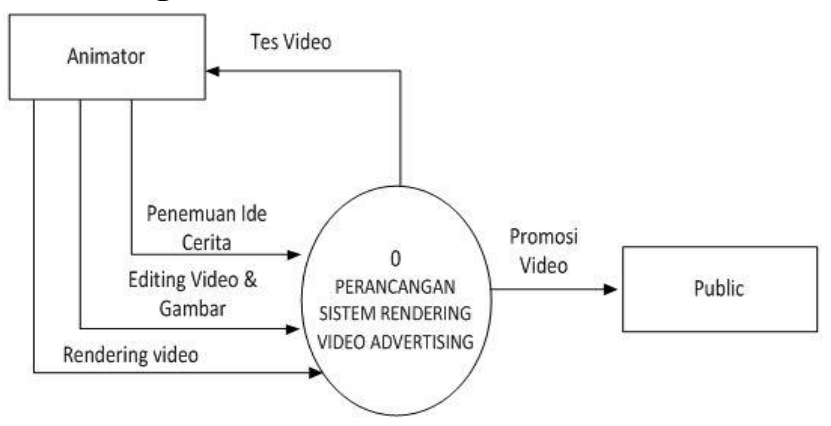

Gambar 3.1 Diagram Konteks

Tabel 1. Keterangan Diagram Konteks

\begin{tabular}{|l|l|}
\hline \multicolumn{2}{|l|}{ Keterangan: } \\
\hline $\begin{array}{l}\text { Tahap Pra } \\
\text { Produksi }\end{array}$ & $\begin{array}{l}\text { Terdiri dari Proses Penemuan ide } \\
\text { cerita, Pengumpulan foto- } \\
\text { foto/gambar, Editing Video dan } \\
\text { gambar dan merendering hasil } \\
\text { editan vidio dan gambar. }\end{array}$ \\
\hline $\begin{array}{l}\text { Output } \\
\text { Produksi }\end{array}$ & Video Advertising \\
\hline $\begin{array}{l}\text { Pasca } \\
\text { Produksi }\end{array}$ & $\begin{array}{l}\text { Rendering Video dan Advertising } \\
\text { video }\end{array}$ \\
\hline Animator & Pembuat video \\
\hline Public & Masyarakat \\
\hline
\end{tabular}

\subsubsection{Diagram Alir Data Level Nol}

Diagram nol adalah diagram yang menggambarkan proses dari data flow diagram. Diagram nol memberikan pandangan secara 
menyeluruh mengenai sistem yang ditangani, menunjukkan tentang fungsi-fungsi utama atau proses yang ada, aliran data, dan eksternal entity.

Tujuan dari diagram level nol adalah untuk "memerinci" sebuah sistem menjadi "prosesproses" yang harus dilakukan.

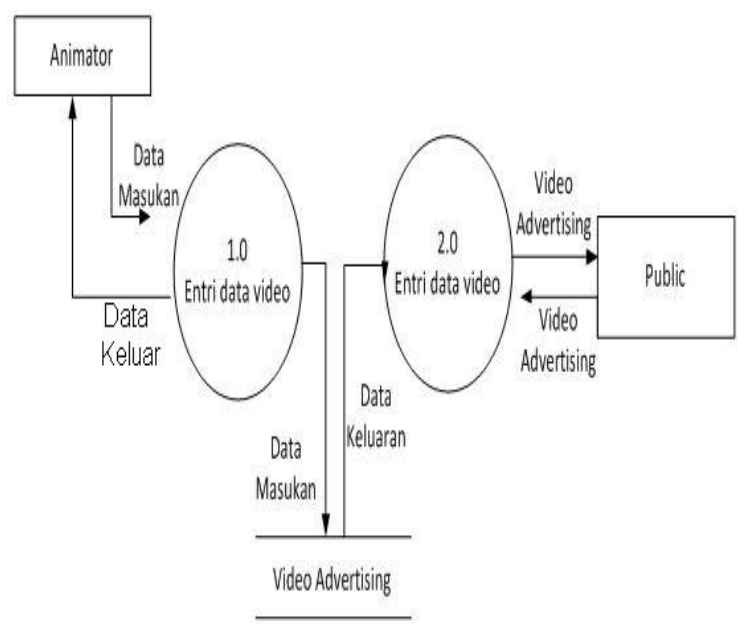

Gambar 3.2 Diagram Alir Data level Nol

\subsection{Tahapan Perancangan Sistem}

Proses produksi video secara garis besar terdiri atas tiga tahap, yaitu: pra produksi, produksi dan pasca-produksi. Masing-masing tahapan mempengaruhi biaya dan kualitas video secara berkelanjutan.

\subsubsection{Pra Produksi}

Tahapan ini adalah tahapan dimana data apa saja yang di butuhkan atau persiapan yang sudah direncanakan dalam pembuatan video ini, mulai dari ide cerita, script writing, storyboarding, gambar-gambar dan video-video. Dalam tahapan ini akan di uraikan satu per satu tahapan dari praproduksi.

\subsubsection{Ide Cerita}

Ide merupakan hal yang mendasar untuk membuat sebuah video. Ide cerita dari rendering video ini adalah menceritakan seorang mahasiswa dari kampus logika yang ingin membuat video advertising yang akan digunakan sebagai media Promosi STMIK LOGIKA.

\subsubsection{Scipt Writing}

Scriptwriting adalah seni penulisan naskah cerita dalam bahasa Indonesia. Apa yang anda lihat, dengar dan saksikan di media-media secara audio dan visual, tidak terlepas dibaliknya adalah rentetan karya seni yang pada awalnya berbentuk script atau naskah, detail dari maksud tujuan hingga karakter, bahkan suasana yang dibangun melalui imajinasi atau gambaran nyata suatu kejadian yang ada sehari-hari hingga peristiwa istimewa yang menjadi ilham dan ruh dari apa yang kita lihat dan saksiskan.

\subsubsection{Storyboarding}

Storyboard adalah serangkaian sketsa yang menggambarkan suatu urutan (alur cerita) elemen - elemen yang akan dimasukkan ke dalam video. Elemen tersebut, seperti : teknik produksi, penempatan animasi dan efek yang cocok dengan skenario.

\subsubsection{Produksi}

Proses produksi video advertising memiliki beberapa tahapan produksi dalam pembuatannya, diantaranya:

\subsubsection{Shooting / Pengambilan gambar}

Proses produksi dalam pembuatan video advertising, diawalin dari Pengambilan gambar. Salah satunya adalah Pembuatan background atau latar belakang dari video yang akan dibuat menjadi hal yang penting. Background disimpan dalam lembaran (layer) tersendiri sesuai dengan ide cerita atau konsep untuk memudahkan animator dalam pengerjaan.

\subsubsection{Capturing}

Capturing merupakan proses memasukkan hasil shooting kedalam komputer. Proses capture video (capturing) adalah proses memindahkan hasil rekaman yang disimpan dalam kaset MiniDV dari kamera ke dalam komputer untuk dijadikan sebuah file dengan format digital (avi). Istilah Digitized karena proses yang merubah analog menjadi file digital yang dikenal oleh komputer.
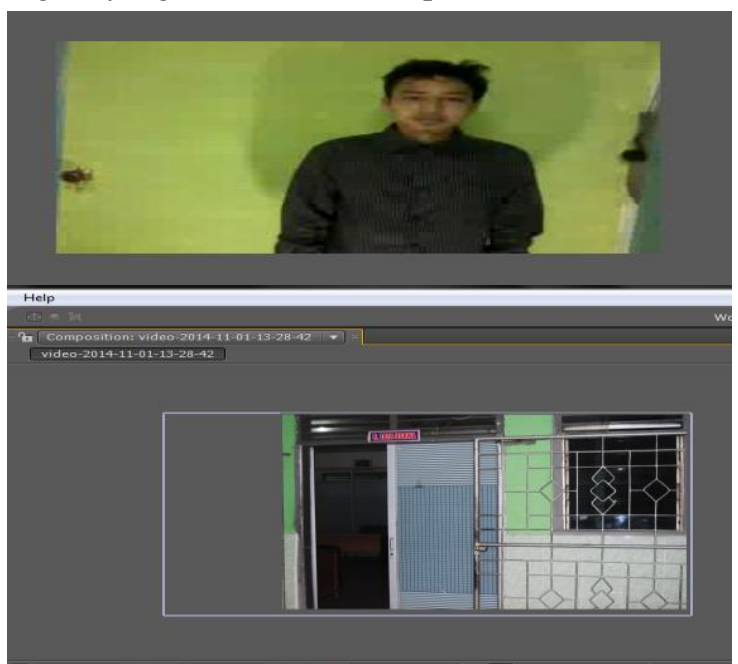

Gambar 3.3. Capturing Background dan Animator 


\subsubsection{Editing}

Setelah semua video dan gambar yang dibutuhkan terkumpul, maka langkah selanjutnya adalah mengedit video dan gambar yang ada sesuai dengan ide cerita. Tema dari hasil ide cerita biasanya menekankan pada satu kata. Sebagai contoh pada perancangan video advertising ini dibuat dengan mengusung tema "Promosi".

\subsubsection{Pasca Produksi}

Dalam proses produksi, hasilnya merupakan sebuah file yang masih belum sempurna, sehingga diperlukannya beberapa tahapan -tahapan, sebagai berikut:

\subsubsection{Pengeditan}

Merupakan proses penyuntingan suatu gambar atau video yang kemudian diberi editan seperti penyisipan-penyisipan efek atau bentuk agar menjadi lebih menarik dan pantas untuk di publish. Editing juga dilakukan agar terjadinya suatu kesatuan urutan sesuai dengan ide cerita. Sehingga cerita yang dibuat pada pra produksi dapat diceritakan dalam bentuk visual.

\subsubsection{Pemberian Efek - Efek Spesial}

Pemberian efek fag 3D pada video Animator digunakan Agar video terlihat lebih nyata atau halus. Tampilan setelah pemberian efek fag 3D pada video

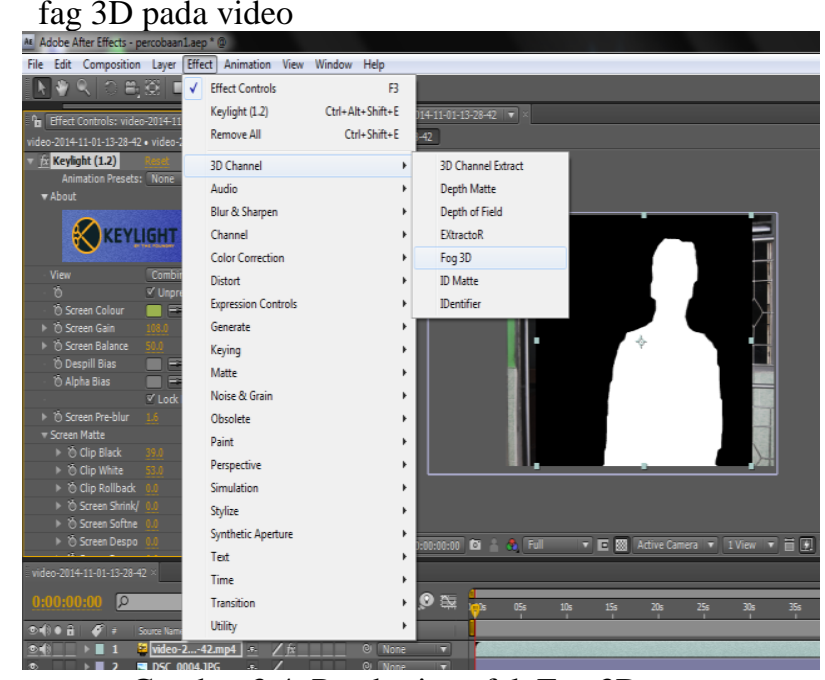

Gambar 3.4. Pemberian efek Fag 3D

\subsection{Rendering Video}

Pada perancangan video advertising ini rendering digunakan untuk menyatukan beberapa gambar-gambar beserta video yang ada. Dan rendering video advertising ini adalah bagaimana jika seorang mahasiswa STMIK Logika mempromosikan kampus STMIK LOGIKA sehingga kemudian dia merancang video advertising sebagai media promosi. [6]

Proses akhir dari keseluruhan proses perancangan video advertising dalam bentuk gambar yang disusun menggunakan program komputer. Dalam rendering, semua data-data yang telah dimasukkan dalam proses pembuatan video akan dihasilkan dalam sebuah bentuk output berupa file-file $s w f$ menjadi sebuah format yang diinginkan dan dapat dinikmatin.

\section{HASIL DAN PEMBAHASAN}

\subsection{Perancangan Proses}

Pengertian implementasi adalah proses penerapan ide, konsep, kebijakan, atau inovasi dalam suatu tindakan praktis sehingga memberikan dampak, baik berupa perubahan, pengetahuan, keterampilan, maupun nilai dan sikap pada suatu objek.

\subsubsection{Produksi}

Proses produksi adalah lanjutan dari proses Pra Produksi sebelumnya. Merekam kejadian langsung, adegan animasi dan suara pada film, videotape atau DV untuk menghasilkan footage/clip disebut dengan "production" atau proses produksi.

Produksi bertujuan untuk memenuhi kebutuhan manusia untuk mencapai kemakmuran.

Produksi juga merupakan Masa selama video diproduksi. Pada tahapan ini dilakukan pekerjaan seperti:

1. Shooting : Pengambilan gambar

2. Capturing : memasukkan hasil shooting kedalam komputer

3. Editing : Melakukan perbaikan atau penyesuaian, seperti : memotong video, membuang bagian yang tidak diperlukan, menggabungkan klip dan menambahkan transisi.

Terkadang terjadi overlapping pekerjaan antara produksi dan pasca produksi terutama pada editing video.

\subsubsection{Shooting Script}

Tujuan membuat Shooting Script ini adalah mengurutkan sebuah naskah cerita yang menguraikan urutan-urutan adegan, tempat, keadaan, dan dialog, yang disusun dalam konteks struktur dramatik. Dalam hal ini langkah awal dalam tahap praproduksi adalah menulis skenario untuk menentukan alur cerita pembuatan iklan.

Pengambilan gambar yang baik akan mempengaruhi kualitas video yang diinginkan. Berikut adalah salah satu lokasi shooting di kampus STMIK Logika Medan yang dipergunakan dalam Perancangan video advertising.

\subsubsection{Capturing}

Capturing merupakan proses memasukkan hasil shooting kedalam komputer. Saat ini, Penulis menjadikan hasil shooting kedalam komputer dengan menggunakan After Effect.

Untuk melakukan Capturing, langkah awalnya adalah membuka software Adobe After 
Effect. Selanjutnya, klik kanan pada software pilih Import $>$ file $(\operatorname{ctrl}+\mathrm{I})$.

\subsubsection{Editing}

Diproses editing video inilah dilakukan pemotongan, pemilihan dan penyusunan ulang gambar, agar sesuai dengan tuntutan skenario. Setelah dilengkapi dengan pekerjan sound, animasi, visual efek dan dianggap selesai, proses editing pun diakhiri dengan outputting, yaitu ekspor ke format file tertentu yang diinginkan untuk proses selanjutnya.

\subsubsection{Pasca Produksi}

Setelah proses produksi maka akan dihasilkan footage atau koleksi klip video. Untuk membangun dan menyampaikan cerita, maka harus mengedit dan menyusun klip-klip tersebut dan tentu saja menambahkan visual effects, gambar, title dan soundtrack. Proses diatas disebut dengan postproduction atau pasca produksi.

Pasca produksi yang penulis buat mencakup dalam 3 hal penting, Yaitu: Pengeditan, Penambahan efek-efek spesial dan Rendering. Pekerjaan yang terdapat pada tahap ini meliputi :

\subsubsection{Pengeditan}

Setelah semua video dan gambar yang dibutuhkan terkumpul, maka langkah selanjutnya adalah mengedit video dan gambar yang ada sesuai dengan ide cerita. Tema dari hasil ide cerita biasanya menekankan pada satu kata. Sebagai contoh pada perancangan Video Advertising ini dibuat dengan mengusung tema "Promosi".

Setelah memberi lingkaran Pen tool pada video terjadi perubahan pada Background belakang tetapi belum sempurna karena masih ada Warna Green.

\subsubsection{Pemberian efek - efek spesial}

Pada gambar di bawah ini sudah mulai terjadi perubahan pada Video Animator dengan layar putih dan hitam menggunakan Efek Keylight.

Setelah pemberian efek pada video menggunakan Keylight, background akan menjadi putih.

Pemberian efek kamera pencahayaan pada pinggiran-pinggiran background agar terlihat lebih baik atau sempurna.

Pemberian effek 3D pada Video Animator digunakan penulis agar video advertising terlihat lebih nyata atau lebih menyatu dengan backgroud.

Tampilan kamera aktif menjadi 2 digunakan untuk mengetahui adanya perubahan pada video dari 3D tersebut. sehingga video yang dihasilkan akan menjadi berbeda dan lebih baik dari sebelumnya.

Hasil akhir dari keseluruhan pemberian Efek-efek atau Rim per rim, lalu Pemberian nama composition yang kita ingginkan

\subsubsection{Rendering}

Rendering adalah proses akhir dari keseluruhan proses pemodelan ataupun animasi komputer. Dalam rendering, semua data-data yang sudah dimasukkan dalam proses modeling, animasi, texturing, pencahayaan dengan parameter tertentu akan diterjemahkan dalam sebuah bentuk output (tampilan akhir pada model dan animasi). (http://wenythepooh.wordpress.com, 2014).

Gambar dibawah ini penginputan atau Audio/ music yang kita inginkan lalu klik ok.

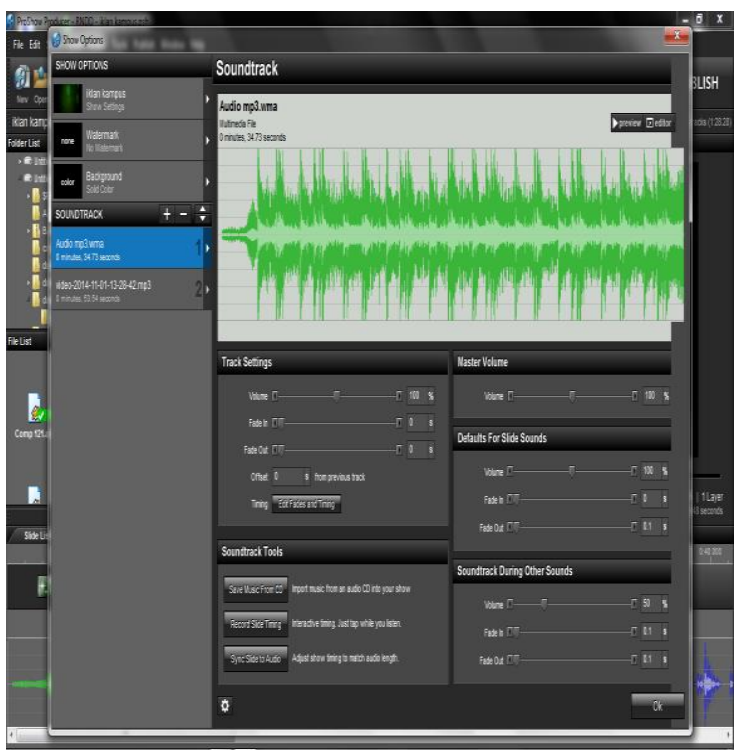

Gambar.4.16. Tampilan Penginputan Audio

\subsection{Proshow}

Proshow merupakan salah satu software Profesional Slideshow. Adanya Wizard Producer pada Proshow yang memungkinkan proses pembuatan video jadi lebih cepat, Banyak style dan transisi di dalamnya. Seperti: Pan, Zoom, 3D, Rotate, Instan Show Creation, keyframe animasi, Trim Video dan Lagu, Mask Adjust, Timing Control, Image Editing, Custom Branding. Menggambungkan semua Projek-projek Video atau Audio yang akan kita campurkan menggunaan Proshow.

\subsection{Rendering Advertising}

Produk video yang telah di buat mungkin selanjutnya akan di distribusikan kepada masyarakat yang merupakan target komunikasi dari produk video advertising. Setelah proses editing video menghasilkan format file tertentu, file ini kemudian dapat diproses lebih lanjut dalam usaha pembuatan VCD atau DVD agar kelak dapat di distribusikan secara massal atau di publikasikan langsung ke sosialmedia seperti facebook dan twitter bahkan youtobe. 


\section{KESIMPULAN}

Dari hasil pembuatan video advertising diatas dan berdasarkan referensi dari beberapa sumber yang sudah dibuat maka dapat disimpulkan bahwa:

1. Pembuatan video advertising membutuhkan waktu, biaya dan perlengkapan peralatan yang sesuai. Selain itu, Imajinasi \& kreativitas yang tinggi.

2. Informasi yang dimasukkan kedalam video sudah sesuai dengan rule dan informasi dari kampus sehingga sangat membantu para pencari informasi, agar lebih memahami tempat yang diinginkan dengan terperinci.

2. Peranan manusia dalam berbagi informasi kepada seluruh lapisan masyarakat khususnya dalam video Advertising dapat digantikan oleh teknologi komputer, salah satunya dengan membuat rendering video advertising.

3. Pemilihan software yang tepat merupakan langkah awal dalam pembuatan video advertising yang baik. After Effect dan Adobe Photoshop CS adalah software yang tepat untuk perancangan pembuatan video advertising.

Menggunakan Sistem Operasi Cross Platform (Linux, Windows, Mac dll) dengan spesifikasi komputer yang lebih tinggi dalam membuat video advertising guna sangat membantu menyelesaikan proses render.

\section{DAFTAR PUSTAKA}

1. http://teg849.wordpress.com/2011/02/27/p roses-rendering-dan-animasi/

2. Menurut Jubilee Enterprise, (2012).

3. Menurut Madcoms (2013),

4. (http://id.wikipedia.org/wiki/Adobe_After _Effects).

5. (www.pendidikanekonomi.com,2013).

6. (http://id.wikipedia.org/wiki/Produksi,201 4)

7. Arbie. 2004.Manajemen Database dengan MySQL. Yogyakarta : Andi

8. Bahra, Al. 2005. Analisis dan Desain Sistem Informasi.Yogyakarta : Graha Ilmu. 